4 Gillon R. AIDS and medical confidentiality. BMJ (Clin Res Ed) 1987; 294: 1675-1677.

5 Matiluko AA, Soundarajan L, Hogston P. Early contraceptive failure of Implanon ${ }^{\circledR}$ in an HIV seropositive patient on triple antiretroviral therapy with zidovudine, lamivudine and efavirenz. J Fam Plann Reprod Health Care 2007; 33: 277-278.

\section{Contraceptive failure and the progestogen-only pill}

The case report by Chandler and Nash ${ }^{1}$ in this issue of the Journal is interesting and highlights the need for trials of hormonal contraceptive use to include obese women.

The authors acknowledge that despite an apparent association between contraceptive failure and higher body weight in studies of a Norplant ${ }^{\circledR}$ prototype and a levonorgestrelreleasing vaginal ring, there is insufficient evidence to demonstrate reduced efficacy in heavier women using the progestogen-only pill (POP). Current guidance from the Faculty of Sexual and Reproductive Healthcare (FSRH) ${ }^{2}$ advises one progestogen-only pill (POP) per day irrespective of body weight. This recommendation is based on the evidence available at the time of publication and the consensus of the guideline development group.

The recent review of obesity and oral contraceptive pill (OCP) failure by Trussell et al. ${ }^{3}$ lends further support to FSRH guidance. The authors conclude that they "found no convincing evidence that very heavy or obese women have a higher risk of oral contraceptive pill [combined and progestogen-only] failure during perfect use than thinner women, even with the lowest doses formulations". Trussell and colleagues mention the difficulties of reliably measuring adherence and they speculate that OCs may be less forgiving of imperfect use among heavier women.

Given that long-acting reversible methods of contraception (LARC) are known to be highly effective and less dependent on adherence than OCs, LARC methods should be offered to all women, particularly following OCP failure.

Louise Melvin, MRCOG, MFSRH

Director, FSRH Clinical Effectiveness Unit, and Consultant in Sexual and Reproductive Health,

Sandyford, Glasgow, UK.

E-mail:louise.melvin@nhs.net

\section{References}

Chandler J, Nash K. Contraceptive failure and the progestogen-only pill: the issue of body weight. $J$ Fam Plann Reprod Health Care 2010; 36: 167-168.

2 Faculty of Sexual and Reproductive Healthcare Clinical Effectiveness Unit. Progestogen-only Pills. 2008. http://www.fsrh.org/admin/uploads/CEU GuidanceProgestogenOnlyPill09.pdf [Accessed 14 May 2010]

3 Trussell J, Schwarz E, Guthrie K. Obesity and oral contraceptive pill failure. Contraception 2009; 79: 334-338.

\section{Lost IUD penetrating bladder wall}

The incidence of uterine perforation following intrauterine device (IUD) insertion is reported to be nearly $0.5-1 / 1000$ insertions. ${ }^{1}$ Misplaced IUDs can be diagnosed simply with speculum examination. Missing threads is the usual sign and may be due to unrecognised expulsion, enlarged uterus due to pregnancy, the IUD threads becoming detached or, most importantly, perforation.

A 48-year-old woman was admitted to our clinic with a suspected misplaced IUD. She had her IUD inserted 15 years ago in a health cabin by a midwife. She started having pelvic pain following insertion; however, this was attributed to the insertion procedure. Four months after the device was introduced the pain diminished and the woman wondered whether in fact the IUD had dropped out. During a routine examination, a clinician interpreted this decreased pelvic pain as a consequence of IUD expulsion. The woman had never experienced any urinary or intestinal symptoms. Of nine vaginal deliveries (gravida 12 , miscarriage 3 ), the last three were planned after supposed IUD loss without any complications. Recently the woman had experienced unacceptable abdominal and pelvic pain and was referred with a suspected lost IUD

Pelvic examination revealed normal findings except for missing IUD threads. Pelvic ultrasonography revealed a hyperechogenic, rodshaped foreign body, possibly the IUD, extending through the dome of the bladder wall. Diagnostic cystoscopy revealed IUD penetration of the bladder. Extraction with forceps only allowed part of the IUD to be pulled. Although sufficien force was exerted, the knob at the base of the device could not be pulled into the bladder. In order not to damage the bladder mucosa, the IUD threads were broken and pulled during cystoscopy and the handle of the device was extracted during laparoscopy (Figure 1) Postoperatively a catheter was held through the bladder for 1 week. The recovery period was uneventful.

Uterine perforation is a potentially hazardous yet uncommon complication of IUD insertion and can go unnoticed due to anticipation of pain during the insertion procedure. Diagnosis is relatively easy if suspicion is awakened. Pelvic ultrasonography is the first step towards establishing the location of a misplaced IUD Computed tomography, magnetic resonance imaging, X-ray and fluoroscopy are also usefu tools for diagnosis; however, in most cases the diagnosis can be made using only simple pelvic ultrasonography.

Zakin et al. divided perforation into two groups: complete and partial. They proposed that once partial perforation had occurred, the IUD may transmigrate to the adjacent structure easily. ${ }^{2}$ Our patient also had multiple pregnancies after IUD insertion. It seems that subsequen pregnancies may have caused the IUD migration. The patient had three deliveries following IUD insertion.

Bleeding problems and menorrhagia are possible outcomes following IUD insertion; however, these symptoms should alert the clinician to other possible complications. Accompanying pelvic pain is also another sign of possible problems. Our patient had pelvic pain for 4 months following IUD insertion and did no attend for a check-up. Because she attributed this pelvic pain to the insertion procedure, the opportunity for an early diagnosis was lost.

Conversely, the patient sought medical help in order to discover whether the device had dropped out and this was associated with decreased pelvic pain following this painful period. Unfortunately, medical staff concurred with the patient's stated belief that the IUD had dropped out, and so did not perform further investigations to confirm or refute this belief. Interestingly the patient experienced no problems afterwards, until the diagnosis of a misplaced IUD nearly 15 years later.

We believe that this is the first case of bladder perforation reported in the scientific literature. It is a matter of debate in this case as to whether the uterus was iatrogenically perforated or whether the IUD moved through the uterine wall during pregnancy. This case also demonstrates an uncommon localisation of an IUD and the close relationship between pelvic pain and IUD misplacement. This case also emphasises the need for regular check-ups following IUD insertion and the need to be suspicious of possible locations other than the uterus. Most importantly, an accurate diagnosis may facilitate the use of endoscopic techniques and result in minimally invasive treatment.

Mehmet Vural, MD

Assistant Professor, Department of Obstetrics and Gynecology, School of Medicine, Harran University, Sanliurfa, Turkey.

E-mail:drmvural@yahoo.com

\section{Harun Toy, MD}

Assistant Professor, Department of Obstetrics and Gynecology, School of Medicine, Harran University, Sanliurfa, Turkey

Hakan Camuzcuoglu, MD

Assistant Professor, Department of Obstetrics and Gynecology, School of Medicine, Harran University, Sanliurfa, Turkey

Burak Sezgin, MD

Doctor, Department of Obstetrics and

Gynecology, School of Medicine, Harran

University, Sanliurfa, Turkey

References

Gentile GP, Siegler AM. The misplaced or missing IUD. Obstet Gynecol Surv 1977; 32: 627-641.

Zakin D, Stern WZ, Rosenblatt R. Complete and partial uterine perforation and embedding following insertion of intrauterine devices. I. Classification, complications, mechanism, incidence, and missing string. Obstet Gynecol Surv 1981; 36: 335-353.

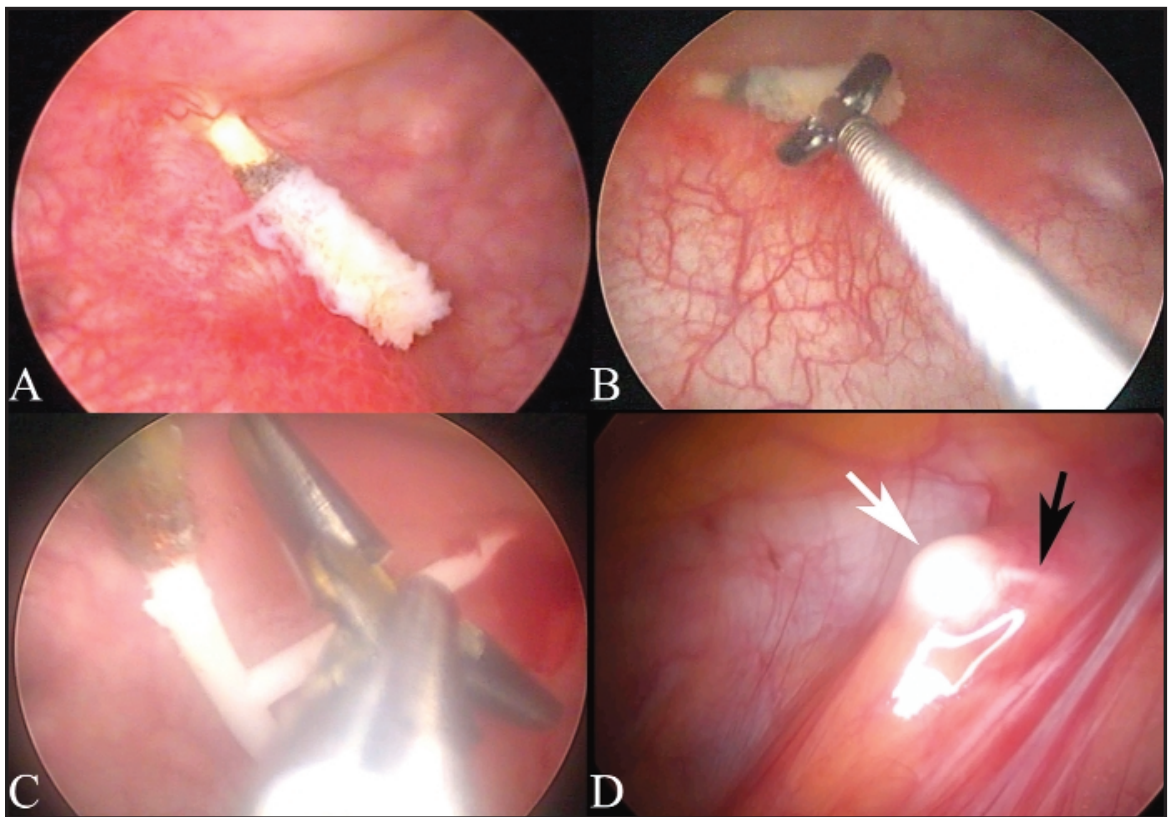

Figure 1 Cystoscopy and laparoscopy images. (A) Only one thread of the T-copper intrauterine device was found to be penetrating the bladder wall. $(B, C)$ Extraction with forceps resulted in the successful traction of the device except for the base and the threads. (D) Using a laparoscopic approach it was possible to extract the remainder of the device after minimal dissection 